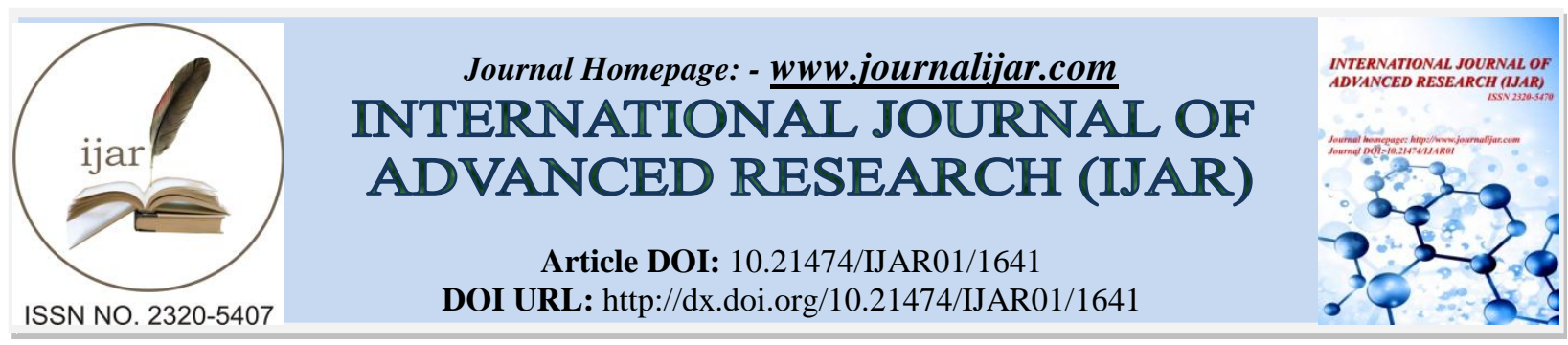

RESEARCH ARTICLE

\title{
ANTIMICROBIAL DIHYDROFLAVONOL FROM SUDANESE CROTON ZAMBESICUS MUELL. ARG.(EUPHORBIACEAE) SEEDS
}

\author{
"Abdel Karim. M. ${ }^{1}$, Nosiba. K. ${ }^{2}$, Fath El-Rahman , A. ${ }^{2}$ and Suad ,A. ${ }^{3}$ \\ 1. Sudan University of Science and Technology, Faculty of Science, Dept. of Chemistry. \\ 2. Omdurman Islamic University, Faculty of Education. \\ 3. Alzaeem Al-Azhari University, Faculty of Education
}

\section{Manuscript Info}

Manuscript History

Received: 13 July 2016

Final Accepted: 19 August 2016

Published: September 2016

Key words:-

Croton zambesicus,Isolation,

Dihydroflavonol,Antimicrobial Activity.

\begin{abstract}
Information on the constituents of the Sudanese material of Croton zambesicus is scarce. Hence this study was designed to investigate the flavonoids of this versatile species and to evaluate its antimicrobial potential in an attempt to establish a rationale for its ethno-medical use. Preliminary phytochemical screening for secondary metabolites revealed the presence of flavonoids, saponins, alkaloids, steroids and tannins in ethanolic extract of Croton Zambesicus seeds. A dihydroflavonol was isolated from the seed extract. The isolate was purified by paper chromatography and identified via a combination of spectral tools (IR, UV, ${ }^{1} \mathrm{HNMR}$ and mass spectroscopy). The isolated compound and the ethanolic extract were evaluated for antimicrobial activity against six standard human pathogens (Bacillus subtilis, Staphylococcus aureus, Pseudomonas aeruginosa, Escherichia coli, Aspergillas niger, candida albicans), and significant results were obtained.
\end{abstract}

Copy Right, IJAR, 2016,. All rights reserved.

\section{Introduction:-}

Croton genus have a long history in the traditional use of medicinal plants in Africa, Asia and South America(Lincy,2011). Plants of this genus are used in treatment of cancer, constipation, diabetes, digestive problems, dysentery, external wounds, fever, hypercholesterolemia, hypertension, inflammation, intestinal worms, malaria, pain, ulcers and weight loss(Anon,1982).

Croton Zambesicus Muell. Arg. , commonly known as "Um-geleigla" in Sudan , belongs to Euphorbiaceae family. It is one of the plants that have wide application in African folkloric medicine(Paul,2002). C.Zambesicus is a large shrub or small tree reaching 16-25 feet in height. The bark is whitish to pale gray, slash, thin and yellowish with strong aromatic odour. Flowers usually occur at the beginning of dry season. It inhabits the Sudan and Guinea Savanna zone and is distributed from Cameroon to tropical Africa(Yurkanis,2004).

Croton zambesicus is a multi-purpose medicinal herb . In Sudan, it is used to make a herbal tea "Umi geleigla tea". It is also given for an array of human disorders(El-Hamidi,1970) including: malaria, fever , skin diseases and urinary tract infections. Root is used in Sudanese folk medicine for menstrual pain(El-Hamidi,1970) and as aperients(Ngadju et.al.,1999). In Nigeria, local healers use roots as antimalarial ,febrifuge and antidiabetic(Okokon 
and Nwafor,2009; Okokon et.al.,2005,2006). Leaf decoction is used by some tribes of Benin as antihypertensive and antiseptic(Adjanoboun et.al.,1989)

Preliminary phytochemical screening of root extract revealed the presence of alkaloids, tannins, anthraquinones, terpenes, saponins and cardiac glycosides (Okokon and Nwafor,2009).A diterpene with cytotoxic potential was reported from leaf extract(Block et.al,2002).Leaf, stem and root extracts are claimed to possess antimicrobial activity (Abo et.al.,1999; Okono and Nwafor,2010).Thus supporting the ethno-medical use of this species. Croton seeds when applied externally act as a powerful local irritant. In high doses the plant acts as a very active drastic purgative(Athaya,1985).

Information on the constituents of the Sudanese material of Croton zambesicus is scarce. Hence this study was designed to investigate the flavonoids of this versatile species and to evaluate its antimicrobial potential in an attempt to establish a rationale for its ethno-medical use .

\section{Materiabls and Methods:-}

Materials:-

Instruments:

- UV- Visible Spectrophotometer( Perkin- Elmer lambda 2 ).

- $\quad$ NMR spectrophotometer (EM-360-300MHZ)

- IR Spectrophotometer(Perkin-Elmer 1310 ) .

- $\quad$ Mass Spectrometer( Finnigan - MAT SQ- 700).

\section{Plant Material:-}

The seeds of Croton Zambesicus were collected in May-2016 from south Kordofan state-western Sudan. The plant was authenticated by the Botany Department, University of Khartoum.

\section{Solvents:L-}

All chemicals, solvents and reagents used were of analytical grade. Chemicals used were supplied by British Drug House (England) and Sigma (Germany). Spectroscopic grade solvents were used for spectral determination and a deuterated solvent(DMSO- $\mathrm{d}_{6}$ ) was used for NMR analysis.

\section{Methods:-}

Phytochemical screening:-

Preliminary phytochemical screening for secondary metabolites was conducted according to the method described by Harborne(1989).

\section{Isolation of flavonoids:-}

Powdered shade- dried seeds (1.5kg) of Croton zambesicus were macerated with 95\% ethanol at room temperature for 48 hours. The solvent was removed under reduced pressure and the crude extract was dissolved in methanol and applied to Whatman paper (No. $3 \mathrm{~mm}-46 \mathrm{x} 57 \mathrm{~cm}$ ). The bands were irrigated with $30 \%$ acetic acid and the developed chromatograms were air-dried and examined under both visible and UV light ( $\kappa 366,245 \mathrm{~nm})$. The equivalent bands from each paper were then cut out, combined and cut into small strips and slurred with absolute ethanol. After several hours of contact with occasional shaking, the liquid was evaporated in vacuo to dryness. In this way a flavonoid-compound I was isolated in chromatographically pure form as yellow powder.

\section{Antimicrobial assay:-}

Compound I and ethanolic extract of Croton zambesicus seeds were evaluated for antimicrobial activity against six standard human pathogens (Bacillus subtilis, Staphylococcus aureus, Pseudomonas aeruginosa, Escherichia coli, Aspergillas niger and Candida albicans) using cup plate agar diffusion assay.

\section{Preparation of bacterial suspensions:-}

One $\mathrm{ml}$ aliquots of a 24 hours broth culture of the test organisms were aseptically distributed onto nutrient agar slopes and incubated at $37^{\circ} \mathrm{C}$ for 24 hours. The bacterial growth was harvested and washed off with $100 \mathrm{ml}$ sterile normal saline, to produce a suspension containing about $10^{8}-10^{9}$ C.F.U/ $\mathrm{ml}$. The suspension was stored in the refrigerator at $4^{\circ} \mathrm{C}$ till used. The average number of viable organisms per $\mathrm{ml}$ of the stock suspension was 
determined by means of the surface viable counting technique(Wikler,2007). Serial dilutions of the stock suspension were made in sterile normal saline solution and $(0.02 \mathrm{ml})$ volumes of the appropriate dilution were transferred by micro pipette onto the surface of dried nutrient agar plates. The plates were allowed to stand for two hours at room temperature for the drops to dry and then incubated at $37^{\circ} \mathrm{C}$ for 24 hours. After incubation, the number of developed colonies in each drop was counted. The average number of colonies per drop $(0.02 \mathrm{ml})$ was multiplied by 50 and by the dilution factor to give the viable count of the stock suspension, expressed as the number of colony forming units per ml suspension.

Each time a fresh stock suspension was prepared. All the above experimental conditions were maintained constant so that suspensions with very close viable counts would be obtained.

\section{Preparation of fungal suspension:-}

The fungal cultures were maintained on dextrose agar, incubated at $25{ }^{\circ} \mathrm{C}$ for 4 days. The fungal growth was harvested and washed with sterile normal saline and finally suspended in $(100 \mathrm{ml})$ of sterile normal saline, and the suspensions were stored in the refrigerator until used.

\section{Testing of antibacterial activity:-}

The cup plate agar diffusion assay-with some minor modifications - was adopted to screen the antibacterial activity. The experiment was carried out according to the National Committee for Clinical Laboratory Standards Guidelines(Wikler,2007).Bacterial suspension was diluted with sterile physiological solution to $10 \mathrm{cfu} / \mathrm{ml}$. One hundred micro-litres of bacterial suspension were swabbed uniformly on surface of MHA and the inoculum was allowed to dry for 5 minutes. Sterilized filter paper discs (Whatman No.1, $6 \mathrm{~mm}$ in diameter) were placed on the surface of the MHA and soaked with $(20 \mu \mathrm{l})$ of test solution. The plates were incubated at $37{ }^{\circ} \mathrm{C}$ for $24 \mathrm{~h}$ in the inverted position. The diameters $(\mathrm{mm})$ of the inhibition zones were measured in triplicates and averaged.

\section{Testing of antifungal activity:-}

The above mentioned method was adopted for antifungal activity, but instead of agar, s dextrose agar was used. Samples were used here by the same concentrations used above.

\section{Results and Discussion:-}

Preliminary phytochemical screening for secondary metabolites revealed the presence of flavonoids, saponins, alkaloids, steroids and tannins in ethanolic extract of Croton Zambesicus seeds.

\section{Characterization of compound I:-}

Compound I was isolated as yellow powder from ethanolic extract of Croton Zambesicus seeds .The IR spectrum of compound I (Fig.1) displayed absorption bands at $v(\mathrm{KBr}): 3382.9(\mathrm{OH}), 2921.9,(\mathrm{C}-\mathrm{H}$, alkane), $1654.81(\mathrm{C}=\mathrm{O})$, 1554.5, $1433(\mathrm{C}=\mathrm{C}$, aromatic), 1238.2 (C-O, ether), and 1049. (C - O, phenolic).

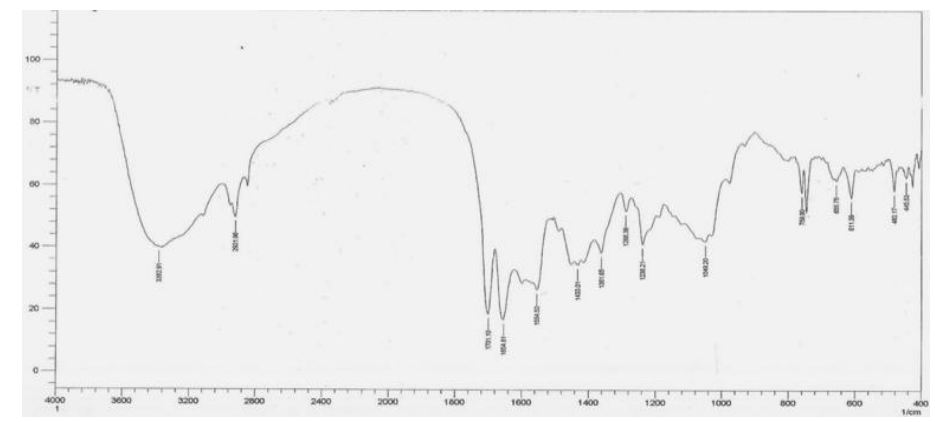

Fig.1:- The IR spectrum of compound I

The UV spectrum (Fig.2) showed $\lambda_{\max }(\mathrm{MeOH}) 266 \mathrm{~nm}$. Since compound I gave only band II it could be (i) a flavanone (ii)dihydoflavanol (iii) isoflavone or (iv) dihydrochalcone(Harborne,1989). 
<smiles>O=C1CC(c2ccccc2)Oc2ccccc21</smiles>

Flavanone<smiles>O=c1c(-c2ccccc2)coc2ccccc12</smiles>

Isoflavone<smiles>O=C1c2ccccc2OC(c2ccccc2)C1O</smiles>

Dihydroflavonol<smiles>O=C(CCc1ccccc1)c1ccccc1</smiles>

Dihydrochalcone

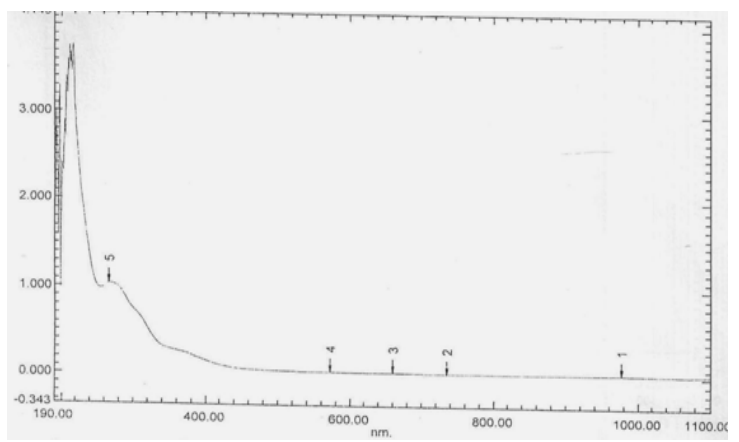

Fig.2:- The UV spectrum of compound I

Isoflavones inconsistently show a shoulder in the 300-340 nm region. Such shoulder was not detected in the spectrum of compound I (Fig.2) and dihydroflavonols possess a 3- OH function which could be confirmed by the shift reagent sodium methoxide(Harborne,1989). The sodium methoxide spectrum (Fig.3) revealed a $15 \mathrm{~nm}$ bathochromic shift with decrease in intensity and this is indicative of $3-\mathrm{OH}$ function.,Hence compound I is a dihydroflavonol. When $\mathrm{NaOAc}$ was added to methanolic solution of compound I, a 13nm bathochromic shift was observed indicating a $7-\mathrm{OH}$ function (Fig.4).

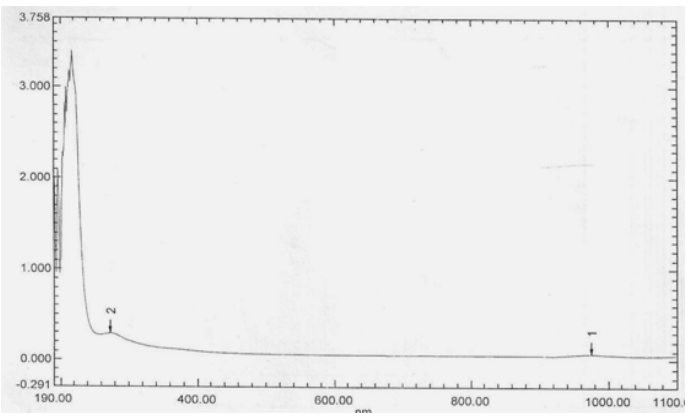

Fig.3:- Sodium methoxide spectrum of compound I 


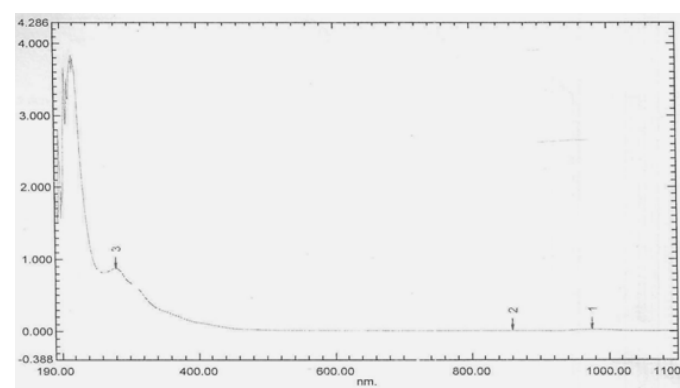

Fig.4:- the sodium acetate spectrum of compound I

The ${ }^{1}$ HNMR spectrum (Fig.5) gave : $\delta 1.20(\mathrm{~s}, 3 \mathrm{H})$ which accounts for a methyl group ; $\delta 1.65(3 \mathrm{H})$ assigned for an acetyl function. The mass spectrum (Fig.6) gave $\mathrm{m} / \mathrm{z} 311\left(\mathrm{M}^{+}\right)$. Other important fragments corresponding to intact aromatic rings, and resulting from retro Diels-Alder cleavage (Scheme I), were shown at $\mathrm{m} / \mathrm{z} 150$ (ring A) and $\mathrm{m} / \mathrm{z}$ 162(ring B). Such peaks provide evidence for the proposed substitution pattern of these aromatic rings. ${ }^{1} \mathrm{H}-{ }^{1} \mathrm{H}$ COSY NMR experiments indicated long range coupling between the acetyl protons and $\mathrm{C}_{3}$ - and $\mathrm{C}_{5}$ - protons. Hence the acetyl function is substituted at $\mathrm{C}_{4}$ of $\mathrm{B}$ ring. A long range coupling between the methyl protons and $\mathrm{C}_{6}$ - proton allowed assignment of the methyl group at $\mathrm{C}_{5}$ of ring $\mathrm{A}$. This is further evidenced by the absence of a lowfield signal for $\mathrm{C}_{5}$ proton around 8.00ppm(Harborne ,1989).

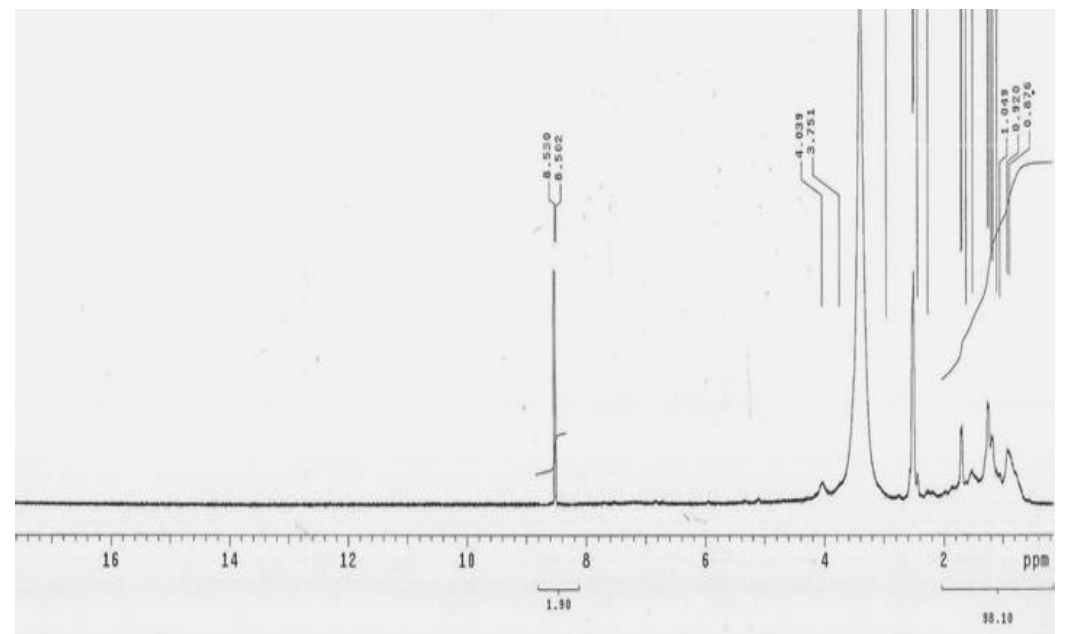

Fig.5:- The ${ }^{1}$ HNMR spectrum of compound I

Comparison with available literature data gave the following structure for compound I :<smiles>CC(=O)c1ccc(C2Oc3cc(O)cc(C)c3C(=O)C2O)cc1</smiles> 


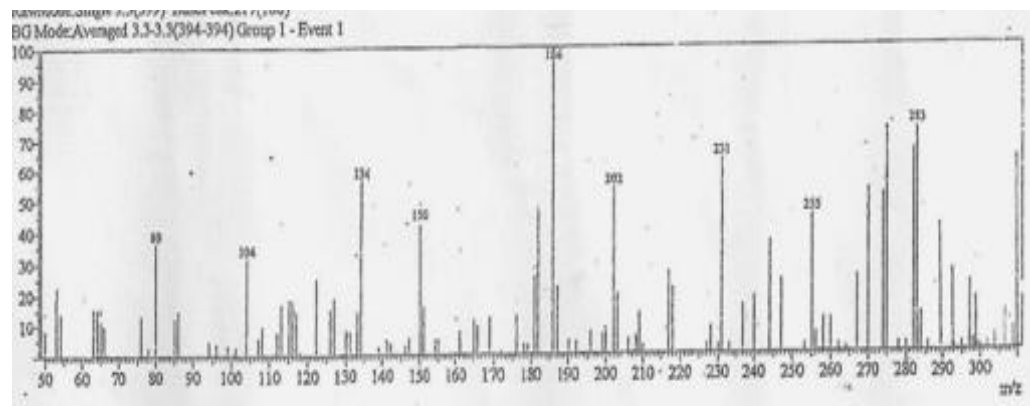

Fig.6:- Mass spectrum of compound I

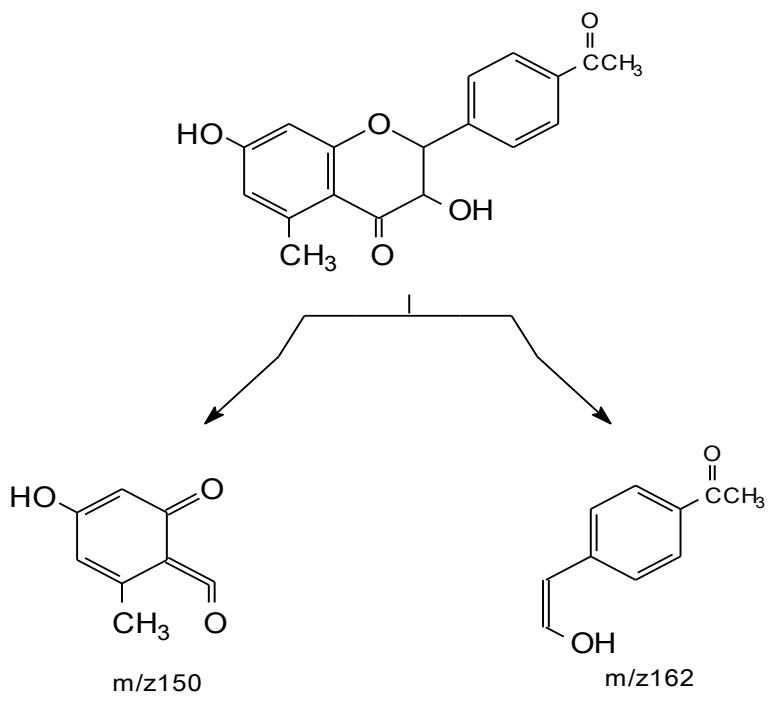

Scheme I :- Retro Diels - Alder fission of compound I

\section{Antimicrobial assay:-}

The cup plate agar diffusion assay was adopted to evaluate the antimicrobial potential of compound I and the ethanolic extract of Croton Zambesicus seeds against six standard human pathogens (Bacillus subtilis, Staphylococcus aureus, Pseudomonas aeruginosa, Escherichia coli, Aspergillas niger, Candida albicans ). The mean diameters of inhibition zones (MDIZ) and the minimum inhibitory concentration (MIC) produced by compound I and ethanolic extract on standard microorganisms are presented in Table (1). The results were interpreted in commonly used terms : (<) $9 \mathrm{~mm}$ : inactive ; $9-12 \mathrm{~mm}$ : partially active ; $13-18 \mathrm{~mm}$ : active; (>) 18 $\mathrm{mm}$ : very active. Tables (2) and (3) represent the antimicrobial activity of standard antibacterial and antifungal chemotherapeutic agents against standard bacteria and fungi respectively. It is clear from Table (1) that the crude ethanolic extract is more potent than compound I. However, compound I showed significant antibacterial activity and moderate antifungal activity against test organisms.

Table 1:- The antibacterial activity of compound I and ethanolic extract

Sa.: Staphylococcus aureus

\begin{tabular}{|l|l|l|l|l|l|l|}
\hline \multirow{3}{*}{ Sample } & \multicolumn{4}{|l|}{ Inhibition zone diameter (mm / mg sample) } \\
\cline { 2 - 7 } & \multicolumn{4}{|l|}{ Antibacterial activity } & \multicolumn{2}{l|}{ Antifungal activity } \\
\cline { 2 - 7 } & Bs. (G+) & Sa. $(\mathrm{G}+)$ & Ec.(G-) & Pa. (G-) & Ca. & An. \\
\hline Control( Methanol) & 00 & 00 & 00 & 00 & 00 & 00 \\
\hline Ethanolic extract(100mg/ml) & 22 & 21 & 22 & 22 & 19 & 16 \\
\hline Comp. I(100mg/ml) & 19 & 17 & 18 & 18 & 15 & 14 \\
\hline
\end{tabular}

Ec.: Escherichia coli

Pa.: Pseudomonas aeruginosa

Bs.: Bacillus subtilis 
An.: Aspergillus niger

Ca.: Candida albicans

Table 2 :- Antibacterial activity of standard chemotherapeutic agents

\begin{tabular}{|l|c|l|l|l|l|}
\hline Drug & Conc.(mg/ml) & Bs & Sa & Ec & Ps \\
\hline Ampicilin & 40 & 15 & 30 & - & - \\
& 20 & 14 & 25 & - & - \\
& 10 & 11 & 15 & - & - \\
\hline Gentamycin & 40 & 25 & 19 & 22 & 21 \\
& 20 & 22 & 18 & 18 & 15 \\
& 10 & 17 & 14 & 15 & 12 \\
\hline
\end{tabular}

Table 3 :- Antifungal activity of standard chemotherapeutic agent

\begin{tabular}{|l|l|l|l|}
\hline Drug & Conc. $(\mathrm{mg} / \mathrm{ml})$ & $\mathrm{An}$ & $\mathrm{Ca}$ \\
\hline Clotrimazole & 30 & 22 & 38 \\
& 15 & 17 & 31 \\
& 7.5 & 16 & 29 \\
\hline
\end{tabular}

\section{References:-}

1. Adjanohoun, E.J., Adjakide, V. and deSouza, S. (1989), Contribution to Ethnobotanical and Floristic Studies in Republic of Benin.Vol.1, Agency for Cultural and Technical Cooperation, p.245.

2. Abo, K.A., Ogunleye, V.O. and Ashidi, J.S. (1999), Phytotherapy research, 13(6), 494.

3. Anon,K. "Medical and Aromatic Plant of the Sudan" Kartoum Trading and Project Company, Khartoum , Sudan,Pamphet.p40 (1982).

4. Athaya, C, D.(1985), Indian Journal of Forestry, 8(2), 137.

5. Block, S., Stevigny, C., Llabres, G., deHoffman, E., Adjakide, V., DePauw-Gillet, M. and Quetin-Leclercq, J. (2002), Planta Medica, 68:, 647.

6. El-Hamidi, A. (1970), Plantae Medica, 18, 278.

7. Harborne, J.B.(1989): In "Methods of Biochemistry", Vol.1, Academic Press, London.

8. Lincy J.M.(2011), International Journal of Pharmaceutical Research, 4, 473.

9. Ngadjui, B.T., Folefoc, G.G., Keumedjio, F., Dango, E., Sondegam, B.L. and Conolly, J.D.(1999), Phytochemistry, 51:, 171.

10. Okokon,J.E., Ofodum, K.C., Ajibesin, K.K., Danladi, B. and Gamaniel, K.S. (2005), Indian Journal of Pharmacology 37(4): 243-246.

11. Okokon, J. E., Bassey, A. L. and Obot, J. (2006) , African Journal of Traditional,Complementary and Alternative Medicine , 3 (2), 21.

12. Okokon, J.E. and Nwafor, P. A. (2009), Journal of Ethnopharmacology, 121, 74 .

13. Okokon JE., Nwafor PA. (2010), Pakistan Journal of Pharmaceutical Sciences, 23(1), 114.

14. Paul ,M.D.(2002) "Medicinal Natural Products", Second Edition, John Willy and Sons,New York.

15. Sebatien, B., Chiara B., and Bernard T.(2004), Phytochemistry ,65,1165.

16. Wikler, M. A., ed. "Performance Standards for Antimicrobial Susceptibility Testing: Seventeenth Informational Supplement, Clinical and Laboratory Standards Institute (2007). 